\title{
Mycoplasma suis in naturally infected pigs: an ultrastructural and morphometric study ${ }^{1}$
}

\author{
Enrique L. Portiansky²*, María A. Quiroga², Mariana A. Machuca² \\ and Carlos J. Perfumo ${ }^{2}$
}

\begin{abstract}
Portiansky E.L., Quiroga M.A., Machuca M.A. \& Perfumo C.J. 2004. Mycoplasma suisin naturally infected pigs: an ultrastructural and morphometric study. Pesquisa Veterinária Brasileira 24(1):1-5. Instituto de Patología, Faculdad de Ciencias Veterinarias, Universidad Nacional de La Plata, Calle 60 y 118, C.C. 296, (1900) La Plata, Buenos Aires, Argentina. E-mail: elporti@fcv.unlp.edu.ar

Swine eperythrozoonosis is a haemotrophic disease caused by Eperythrozoon suis, actually called Mycoplasma suis, an extracellular bacterial organism that apparently adheres to pig erythrocyte membrane, inducing its deformation and damage. Since little is known about the ultrastructural and morphometrical aspects of this microorganism, the present work aimed to deal with these issues. The ultrastructural study revealed the presence of structures corresponding to tubules disseminated throughout the soma of M. suis. A variable separation between the microorganism membrane and that of the erythrocyte was also observed. The structural and positional attitude of $\mathrm{M}$. suis could allow speculation about its mechanism of action.
\end{abstract}

INDEX TERMS: Eperythrozoonosis, Mycoplasma suis, ultrastructure, morphometry, pathogenesis.

\begin{abstract}
RESUMO.- [M ycoplasma suis em suínos naturalmente infectados: um estudo ultra-estrutural e morfométrico.] A eperitrozoonose suína é uma doença hemotrópica causada por Eperitrozoon suis, atualmente denominado Mycoplasma suis, uma bactéria extracelular que, aparentemente, adere à membrana dos eritrócitos suínos, induzindo sua deformação e lesionando-0s. 0 presente trabalho busca estabelecer os aspectos estruturais e ultra-estruturais, pouco conhecidos, deste microorganismo. 0 estudo ultra-estrutural revelou a presença de estruturas correspondentes a túbulos disseminados no soma bacteriano. Observou-se também uma separação variável entre a membrana do microorganismo e a parede do eritrócito. 0 estudo morfométrico e a localização de $M$. suis pode permitir especulação sobre seu mecanismo de ação.
\end{abstract}

TERMOS DE INDEXAÇÃO: Eperitrozoonose, Mycoplasma suis, ultraestrutura, morfometria, patogenia.

\footnotetext{
${ }^{1}$ Received on August 27, 2003.

Accepted for publication on September 12, 2003.

${ }^{2}$ Instituto de Patología, Faculdad de Ciencias Veterinarias, Universidad Nacional de La Plata, Calle 60 y 118, C.C. 296, (1900) La Plata, Buenos Aires, Argentina.

*Author to whom correspondence. E-mail: elporti@ fcv.unlp.edu.ar
}

\section{INTRODUCTION}

Eperythrozoonosis is a haemotrophic disease in swine caused by a bacterium formerly classified as the rickettsial agent Eperythrozoon suis (Hoelzle et al. 2003). The disease is clinically characterized by anemia, jaundice and a variety of associated syndromes (Hsu 1986, Henderson et al. 1997, Machuca et al. 1999).

Eperythrozoon suis, now allocated to the genus Mycoplasma, is an extracellular bacterial organism that attaches to and causes deformity and damage to porcine red blood cells (Hoelzle et al. 2003). The accepted actual name of the agent is Mycoplasma suis (Neimark et al. 2002). It has a restrictive cellular membrane, lacking organelles and nucleus. Its cytoplasm contains as much DNA as RNA (Gwaltney 1995, Gresham 1996). Mycoplasma suis can be identified by optic microscopy in Romanowsky stained blood smears (Gwaltney 1995). It may be round, oval or ring-shaped with diameters ranging from $0.8 \mu \mathrm{m}$ to $2.5 \mu \mathrm{m}$ or even larger (Kreier \& Ristic 1984, Gwaltney 1995).

Although the pathogenesis of the disease is not completely known, it is considered that once M.suis comes into contact with the erythrocyte, it uses the plasmatic glucose for its own metabolism. On the other hand, upon damaging the cellular membrane of the red blood cell, it would induce the 
Enrique L. Portiansky et al.

production of autoagglutinins, favoring agglutination of these cells and their removal by way of the phagocyte-mononuclear system (Gwaltney 1995, Gresham 1996).

Since little is known about the structural (morphometric) and ultrastructural aspects of this microorganism (Pospichil \& Hoffmann 1982), the goal of the present work was to obtain more details regarding its morphology that could explain its pathogenesis.

\section{MATERIALS AND METHODS}

Blood samples were obtained from 27 naturally infected feeder male and female pigs, from a semi-intensive establishment located in the town of Junín, Buenos Aires Province, Argentina. The samples were obtained by venipuncture of the anterior cava vein, using ethylendiaminotetracetic acid (EDTA) as anticoagulant, in a concentration of $0.1 \mathrm{mg} / \mathrm{ml}$ of blood. The samples thus obtained were centrifuged at $800 \mathrm{rpm}$, for $5 \mathrm{~min}$. Later, the cells were washed 3 times with PBS, for 5 min each time. The washed samples were fixed in $2 \%$ glutaraldehyde solution. After $30 \mathrm{~min}$, the pellet was broken into small pieces, which were left in contact with the fixer for another $30 \mathrm{~min}$. The fragments were later washed 3 times with PBS and post-fixed with osmium tetroxide, for $30 \mathrm{~min}$. After dehydration of the samples, they were infiltrated and embedded with epoxi resins (Quetol 812, Nisshin EM Co. Ltd, Tokyo, Japan). Blood smears were stained with May-Grünwald-Giemsa and Wright stains.

Semi-thin $1 \mathrm{~mm}$ thick cuts were obtained using an ultramicrotome. The samples were stained with methylene blue and a "Multiple Stain" solution (Polysciences Inc., Warrington, USA) and observed with an optic microscope. Ultra-thin cuts were stained with uranyl acetate/lead citrate and observed with a transmission electronic microscope JEM-1200 (JEOL Co. Ltd, Tokyo, Japan).

Images of blood smears and semi-thin cuts were captured from a microscope (Olympus BX50 system microscope, Tokyo, Japan) with a microscopic magnification of $x 100$, through an analogical RGB video-camera (Sony DXC-151A CCD, Tokyo, Japan) and digitized with a frame grabber (Flashpoint 128, Integral Technologies Inc., Indianapolis, IN, USA) connected to a computer. Images were processed using the Image-Pro Plus v4.50 software (Media Cybernetics, Silver Spring, MA, USA), with a depth of pixel of 24 bits, RGB and TIFF format. The resolution of the microscopic images was of $640 \times 480$ pixels with a spatial calibration yield of $0.13 \mu \mathrm{m} / \mathrm{pixel}$. The photographs obtained with the electron microscope were digitized through a full-page scanner (Microtek Scanmaker E6, Rotterdam, Holland), with a resolution of $300 \mathrm{ppp}$. In order to separate the desired object from the rest of the tissue, color segmentation, based on the optical density of the object, was issued. Once separated from the rest of the image, the object was quantitatively characterized based on its area (in $\mu \mathrm{m}^{2}$ ), major and minor axis (to obtain the aspect of the object), maximum and minimum diameter, perimeter and roundness, all of them measured in lineal $\mu \mathrm{m}$. Table 1 describes the morphometric parameters evaluated.

\section{RESULTS}

The blood smears revealed the presence of Mycoplasma suis in close contact with the red blood cells (Fig. 1a). The stained semi-thin cuts showed a regular quantity of spherical elements appearing alone or in groups of 2 or 3 , stuck to the membrane of the erythrocyte or free among the red blood cells (Fig. 1b).
Table 1. Morphometric parameters used to evaluate Mycoplasma suis characteristics

\begin{tabular}{ll}
\hline \multicolumn{1}{c}{ Parameter } & \multicolumn{1}{c}{ Description } \\
\hline Area & $\begin{array}{l}\text { Reports the area of each object } \\
\text { Aspect }\end{array}$ \\
& $\begin{array}{l}\text { Reports the ratio between the major axis and the minor } \\
\text { axis of the ellipse equivalent to the object (i.e., an ellipse } \\
\text { with the same area, first and second degree moments), as } \\
\text { determined by Major Axis/Minor Axis }\end{array}$ \\
Major Axis & $\begin{array}{l}\text { Reports the length of the main axis of the ellipse equivalent } \\
\text { to the object (i.e., an ellipse with the same area, first and } \\
\text { second degree moments) }\end{array}$
\end{tabular}

Minor Axis Reports the length of the minor axis of the ellipse equivalent to the object (i.e., an ellipse with the same area, first and second degree moments)

Max. Diameter Reports the length of the longest line that can be drawn to pass through the centroid position and join two points on each object's perimeter

Min. Diameter Reports the length of the shortest line that can be drawn to pass through the centroid position and join two points on each object's perimeter

Max. Distance Reports the maximal separation between Mycoplasma suis and the red blood cell membrane

Min. Distance Reports the minimal separation between M. suis and the red blood cell membrane

Perimeter Reports the length of the outline of each object

Roundness Reports the roundness of each object, as determined by the following formula: (perimeter $\left.{ }^{2}\right) /(4 p *$ area). Circular objects will have a roundness $=1$; other shapes will have a roundness $>1$

Fig.1c shows a magnification of M.suis in a red blood cell membrane. Fig.1d shows a 3D-like image obtained by a filtering process, in which a depression of the erythrocyte membrane surrounding $M$. suis can be observed. A higher magnification of the microorganism and the depression it produces on the red blood cell surface membrane can be observed in Fig.le.

The ultra-structural studies revealed some morphological details of the M. suis. The organisms were observed as round or oval structures, limited by a membrane (Fig.2a). Neither cellular organelles nor nuclear elements were observed. In some cases, widespread electron-dense granules were identified in the cytoplasm. Some microorganisms evidenced structures similar to microtubules. Although M. suis was present on the plasma membrane of the erythrocyte, in most cases a separation between both structures was observed. No cellular membrane damage was detected in the red blood cells, although some irregularities in the shape of the infected erythrocyte were observed on many occasions (Fig.2b).

Table 2 shows the morphometrical values obtained from the light and electron microscopy studies. These values are the average of at least 30 images obtained from each analyzed sample. It was observed that there is coincidence between the major and minor axes and the maximum and minimum diameters, respectively. The electron microscopic data demonstrate that a distance of 37 to $64 \mathrm{~nm}$ separates those parasites that are not touching the erythrocytes from these cells. The real and calculated data for the inner tubule-like 

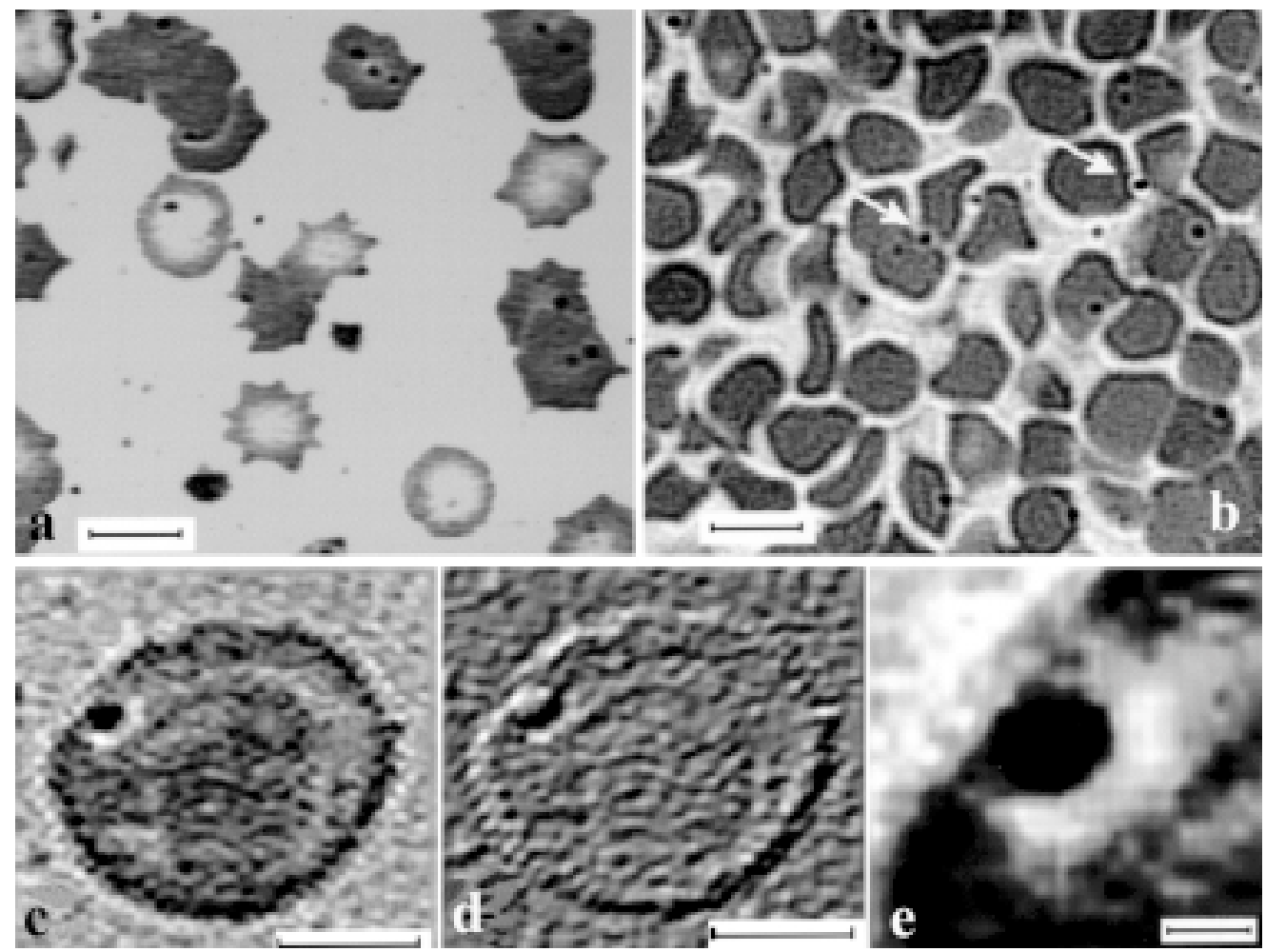

Fig. 1. Blood smears (a) and semi-thin cuts (b) showing spherical elements corresponding to Mycoplasma suis in close contact with the red blood cells (100x). Arrows point to the microorganism attached to two erythrocytes; Magnification (2x) of an erythrocyte appearing in (a) infected with $M$. suis (c); The same cell as in (c) with a 3D-like aspect obtained by filtering process; Magnification (4X) of M. suis (a) and the depression it produces on the erythrocyte surface membrane. Bars represent either $5 \mu \mathrm{m}$ $(\mathrm{a}, \mathrm{b}) ; 1 \mu \mathrm{m}(\mathrm{c}, \mathrm{d})$ or $0.25 \mu \mathrm{m}(\mathrm{e})$.

structures of M.suis (Fig. 3a,b), maintain certain proportion. The calculated values were obtained from measurements
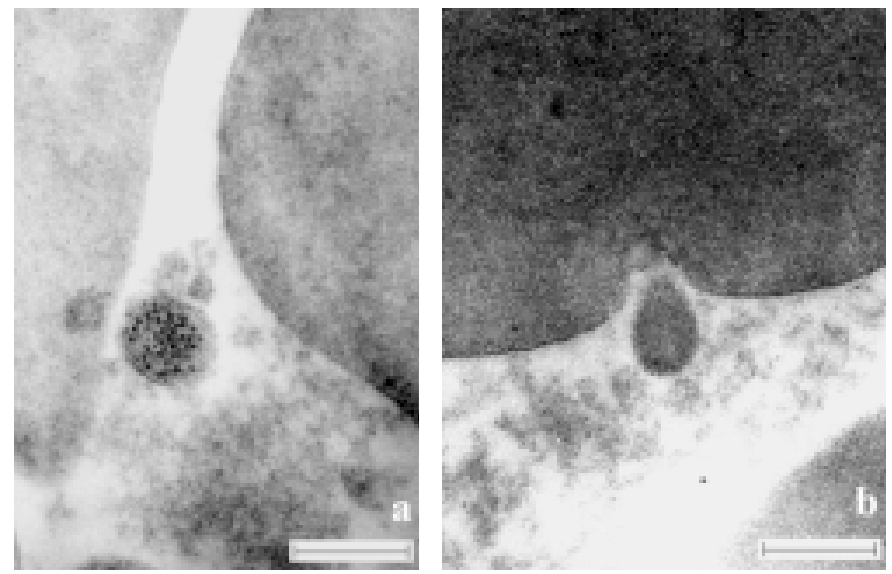

Fig. 2. Electron microscopic photographs showing a spherical structure corresponding to Mycoplasma suis (a). Widespread electron-dense granules were identified in the cytoplasm that resemble microtubules. $M$. suis could also be observed as an oval structure (b). Although no cellular membrane damage was detected some irregularities in the shape of the infected erythrocyte could be observed. In neither case is M. suis touching the red blood cell it infects. Bars represent $400 \mathrm{~nm}$. taken after a filtration process on the images from the electron microscope. The filtration process preserved just the desired objects for measuring at the expense of some image modifications. Since certain proportion exists, a correction index can be established for the filtered images. The area fraction of the real and calculated values of the tubules is shown in Table 3. In both cases the values are quite similar.

\section{DISCUSSION}

Swine eperythrozoonosis is a contagious disease characterized by a marked paleness of the mucous surfaces, presence of blood of watery aspect, delay of growth and increase of
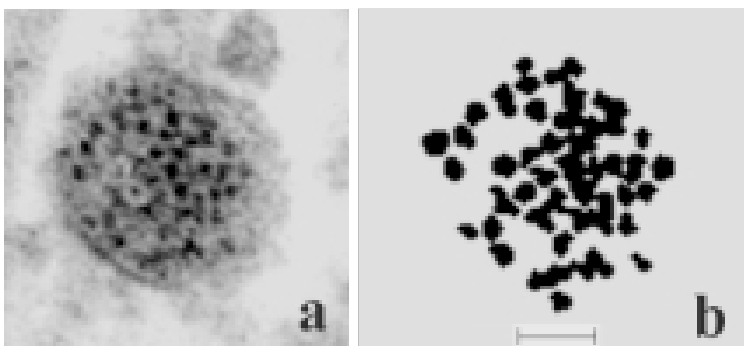

Fig. 3. Mycoplasma suis showing electron-dense structures resembling tubules (a). The same dense structures after thresholding the previous image (b). Bar represents $100 \mathrm{~nm}$. 
Table 2. Morphometrical values of Mycoplasma suis obtained from light and electron microscopy

\begin{tabular}{lcccccc}
\hline Measurements $^{\mathrm{a}}$ & \multicolumn{2}{c}{ M. suis soma (LM values) } & & \multicolumn{3}{c}{ Tubules-like structures (EM Values) } \\
\cline { 2 - 3 } \cline { 5 - 6 } & Blood smears & Semi-thin cuts & & Grid & Real values & Calculated values \\
\hline Area & $0.33 \pm 0.07$ & $0.18 \pm 0.06$ & & $0.17 \pm 0.09$ & $221.47 \pm 126.55$ & $304.08 \pm 169.20$ \\
Major axis & $0.65 \pm 0.06$ & $0.57 \pm 0.11$ & & $0.49 \pm 0.27$ & $20.94 \pm 8.00$ & $23.14 \pm 7.79$ \\
Minor axis & $0.57 \pm 0.08$ & $0.39 \pm 0.09$ & & $0.44 \pm 0.21$ & $12.95 \pm 4.73$ & $16.11 \pm 4.60$ \\
Aspect & $1.14 \pm 0.31$ & $1.49 \pm 0.38$ & & $1.11 \pm 0.24$ & $1.79 \pm 0.68$ & $1.46 \pm 0.30$ \\
Max. Diameter & $0.66 \pm 0.04$ & $0.57 \pm 0.11$ & & $0.49 \pm 0.29$ & $20.31 \pm 7.04$ & $22.78 \pm 7.32$ \\
Min. Diameter & $0.57 \pm 0.08$ & $0.39 \pm 0.09$ & & $0.45 \pm 0.26$ & $12.76 \pm 4.63$ & $15.51 \pm 3.66$ \\
Avrg. Diameter & $0.61 \pm 0.06$ & $0.48 \pm 0.09$ & & $0.47 \pm 0.28$ & $16.55 \pm 5.37$ & $19.17 \pm 4.82$ \\
Perimeter & $1.23 \pm 0.19$ & $1.07 \pm 0.35$ & & $1.47 \pm 0.86$ & $42.58 \pm 21.61$ & $51.71 \pm 24.23$ \\
Roundness & $1.00 \pm 0.00$ & $1.00 \pm 0.00$ & & $1.01 \pm 0.05$ & $1.03 \pm 0.10$ & $1.02 \pm 0.13$ \\
Max. Distance & & & & 64 & & \\
Min. Distance & & & 37 & &
\end{tabular}

area values are expressed either in $\mu \mathrm{m}^{2}$ (M. suis soma) or $\mathrm{nm}^{2}$ (tubules). All other values are expressed either in $\mu \mathrm{m}$ (M. suis soma) or nm (tubules). Tubules values represent each tubule characteristic. Maximal and minimal distance between $M$. suis and a red blood cell membrane are expressed in $\mathrm{nm}$. Values represent the average of at least 30 images \pm SD. $L M=$ Light microscopy. EM = electron microscopy.

Table 3. Area fraction of inner tubules-like structures of Mycoplasma suis

\begin{tabular}{|c|c|c|c|}
\hline $\begin{array}{c}\text { Total } \\
\text { number of } \\
\text { tubules }\end{array}$ & Total tubule area & M. suis area & $\begin{array}{c}\text { Area } \\
\text { fraction }\end{array}$ \\
\hline
\end{tabular}

Real values $44 \pm 11 \quad 25437.09 \pm 1392.05 \quad 117911.60 \pm 21758.02 \quad 21.57 \%$ $\begin{array}{llll}\text { Calculated } \quad 35 \pm 5 \quad 23406.58 \pm 846.00 & 117911.60 \pm 21758.02 & 19.85 \%\end{array}$ values

area values are expressed in $\mathrm{nm}^{2}$.

mortality in feeder pigs, with a death toll that ranges between $3.1 \%$ and $18.7 \%$ monthly. Mycoplasma suis can be detected by light microscopy in Romanowsky stained blood smears (Gresham 1996). In our work, round elements were observed ranging from 0.25 to $0.40 \mu \mathrm{m}$, stuck to the membrane of the erythrocyte in coincidence with those described by other authors (Hsu 1986, Solignac et al. 1996). In the $1 \mu \mathrm{m}$ semithin cuts similar structures were observed but with smaller dimensions. This could be attributed to the stretching of the cells in the smears.

The ultrastructural study revealed some details of the morphology of M. suis. Although an apparent contact was observed between the microorganism and the erythrocyte in the semi-thin cuts, the ultrastructural studies revealed a separation ranging from 37 to $64 \mathrm{~nm}$ between the red blood cell membrane and $M$. suis. The closeness of the structures persisted even after the blood samples had been washed, lasting few free elements among the cells. Most of the infected erythrocytes showed variations in the contour of their membrane at the point of contact with the microorganism, but did not show any damage. These observations coincide with those described by Pospichil \& Hoffmann (1982).

According to the morphometrical values obtained, a concordance between the major and minor axes and the maximum and minimum diameters, respectively, was observed.
This fact endorses the roundness equal to 1 . This means that $M$. suis has a spherical form although the ultra-structural study revealed that $M$. suis presents an oval shape on certain occasions.

As described for other microorganisms, the microtubules observed in the cytoplasm of some M. suis could be a part of its cytoskeleton (Ghadially 1988). On the other hand, and keeping in mind that this microorganism uses the plasma glucose for its own metabolism (Gwaltney 1995), the microtubules could demarcate channels through which the transport of necessary products would take place. This allows us to speculate that $M$. suis does not need the physical atmosphere of the red blood cells to live and reproduce, but simply its nutrients, and that the destruction of the erythrocyte by exhaustion of its reserves would not necessarily signify the destruction of the agent, which would simply move in search of its next target cell.

The described morphometric details constitute an interesting fact for themselves, as they had never been depicted for $M$. suis. The use of an automated image analyzer allows objective appreciation, repetition of the measurements and simple operation. Data related to $M$. suis can thus be analyzed starting from blood smears as well as from semithin cuts. This allows a good diagnosis at a relative speed. The fine detail, represented by the presence of microtubules and the separation of $M$. suis from the erythrocyte membrane, adds to the precision of the diagnosis and leaves an open door to the analysis of a possible pathogenesis of the infection.

There are bacteria that interact with their target cells through a heterotypic union of surface glycoproteins to further internalize them by attaching to their cytoskeleton (Cossart \& Bierne 2001). Although no surface proteins have been identified in the bacteria yet, it could be speculated that M.suis might interact with the erythrocyte in a similar fashion but without entering into the cell.

In conclusion, the use of the optic and electron microscope 
in combination with an image analyzer would allow not only the diagnosis of an infection, as in eperythrozoonosis, but also the analysis of possible mechanisms of action.

Acknowledgements.- The authors wish to thank Silvina Viviana Macnie for her skillful technical assistance in the proof reading of the manuscript. The technical assistance of Mr. Silvio Igal of the Servicio Central de Microscopía Electrónica, Facultad de Ciencias Veterinarias, Universidad Nacional de La Plata, is acknowledged. This study was partially supported by a grant from the Consejo Nacional de Ciencia y Tecnología (CONICET) and from the Secretaría de Ciencia y Técnica, Universidad Nacional de La Plata. ELP is a Research Career Member of CONICET.

\section{REFERENCES}

Cossart P. \& Bierne H. 2001. The use of host cell machinery in the pathogenesis of Listeria monocytogenes. Curr. Opin. Immunol. 13:96-103.

Ghadially F.N. 1988. Microtubules, p. 937-952. In: Ghadially F.N. (ed.) Ultrastructural Pathology of the Cell and Matrix. Vol. 2. 3rd ed. Butterworths, London.

Gresham A.C. 1996. Eperythrozoon infection in pigs. Pig J. 37:20-26.

Gwaltney S.M. 1995. Eperythrozoon suis infections in pigs: clinical syndromes and diagnosis. J. Swine Health Prod. 3:25-27.
Henderson J.P., O' hagan J., Hawe S.M. \& Pratt M.C.H. 1997. Anaemia and low viability in piglets infected with Eperythrozoon suis. Vet. Rec. 140:144-146.

Hoelzle L.E., Adelt D., Hoelzle K., Heinritzi K. \& Wittenbrink M.M. 2003. Development of a diagnostic PCR assay based on novel DNA sequences for the detection of Mycoplasma suis (Eperythrozoon suis) in porcine blood. Vet. Microbiol. 93:185-196.

Hsu F.S. 1986. Pathological features of naturally occurring porcine eperythrozoonosis, p. 372. In: Proc. 9th Int. Pig Veterinary Society Congress, Barcelona, Spain.

Kreier J.P. \& Ristic M. 1984. Eperythrozoon, p. 726-729. In: Kreig N.R. \& Holt J.G. (ed.) Bergey's Manual of Systematic Bacteriology. Vol. 1. 1st ed. Williams $\&$ Wilkins, Baltimore.

Machuca M., Quiroga M.A., Armocida A.D., Arauz S., Idiart J.R., Stornelli M.A. \& Perfumo C.J. 1999. Eperitrozoonosis porcina: descripción de un brote en la provincia de Buenos Aires. Revta Med. Vet. 80:470-474.

Neimark H., Johansson K.E., Rikihisa Y. \& Tully J.G. 2002. Revision of haemotrophic Mycoplasma species names. Int. J. Syst. Evol. Microbiol. 52:683.

Pospichil A. \& Hoffmann R. 1982. Eperythrozoon suis in naturally infected pigs: a light and electron microscopic study. Vet. Pathol. 19:651-657.

Solignac T., Nicolas Y., Fourchon P. \& Blaisot S. 1996. Eperythrozoonosis in swine: identification in french herds, p. 368. In: Proc. 14th Int. Pig Veterinary Society Congress, Bologna, Italy. 